\title{
Study on impact properties of Ti6211 titanium alloy at different temperatures
}

\author{
Yanwen Tian ${ }^{1,}{ }^{*}$, Fang Hao ${ }^{1,2}$, Enen Xu ${ }^{1}$, Junqi Du ${ }^{1}$ \\ ${ }^{1}$ Western superconducting Technologies Co., Ltd.,Xi'an, 710018 China \\ ${ }^{2}$ Northwest Polytechnical University, Xi'an, 710018 China \\ *freedomtyw@163.com
}

\begin{abstract}
$\underline{\text { Abstract }}$
In this paper, Charpy notched pendulum test was used to study the impact properties of Ti6211 titanium alloy at $-60{ }^{\circ} \mathrm{C}$, -40 ${ }^{\circ} \mathrm{C},-20{ }^{\circ} \mathrm{C}, 23{ }^{\circ} \mathrm{C}, 100{ }^{\circ} \mathrm{C}, 200{ }^{\circ} \mathrm{C}$ and $300{ }^{\circ} \mathrm{C}$, respectively, and the fracture morphology was analyzed. The ductile and brittle transition temperature of the material was deduced from the area of the radiation zone. The results show that with the increase of temperature, the impact energy of the alloy increases continuously, and when the temperature reaches above $0{ }^{\circ} \mathrm{C}$, the impact energy increases obviously, and the area of the radiative area of the fracture surface increases gradually. Which can be inferred that the ductile and brittle transition temperature of the alloy is about $50{ }^{\circ} \mathrm{C}$.
\end{abstract}

\section{Introduction}

The theoretical composition of Ti6211 titanium alloy is Ti-6Al-2Zr-1Mo-1V, which is a kind of near $\alpha$ type titanium alloy with high $\mathrm{Al}$ equivalent. Because of its moderate room temperature strength and high temperature strength, good creep resistance, corrosion resistance and welding performance, it can work at $500{ }^{\circ} \mathrm{C}$ for a long time, so it is often used as the bearing part of aircraft engine in aeronautical field. However, the deformation stress caused by some parts subjected to impact load is much larger than that caused by static load. In this paper, Charpy notched pendulum test is used to study the change of impact properties of Ti6211 titanium alloy at different temperatures. And its fracture morphology was also studied. The ductile-brittle transition temperature was deduced from the area of the radiation zone, which provided theoretical guidance for the application of Ti6211 titanium alloy.

\section{Materials and experiments}

The Ti6211 titanium alloy produced by our company is used in this experiment, the specification is $\Phi 300$. The chemical composition of the material is shown in Table 1. The metallographic structure is shown in figure 1. It can be seen from the figure that the material is a typical thermal processing structure in $\alpha-\beta$ two-phase region, which is mainly composed of equiaxed primary $\alpha$ phase and $\beta$ transition structure, in which the secondary $\alpha$ phase in $\beta$ transition is distributed uniformly in lamellar layers.

Table 1 The composition of Ti6211 titanium alloy used in the experiment

\begin{tabular}{|ccccccc|}
\hline $\mathrm{Ti}$ & $\mathrm{Al}$ & $\mathrm{Mo}$ & $\mathrm{Zr}$ & $\mathrm{Si}$ & $\mathrm{V}$ & $\mathrm{Fe}$ \\
\hline Matrix & 6.85 & 1.81 & 2.32 & 0.032 & 2.35 & 0.1 \\
\hline
\end{tabular}




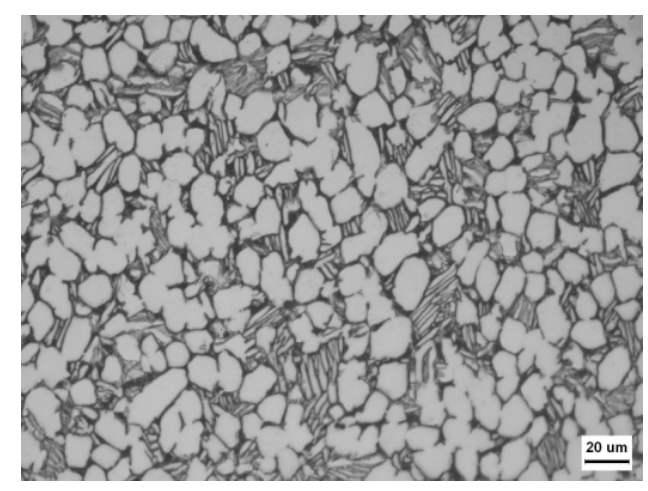

Fig 1 The metallographic photographs of Ti6211 titanium alloy used in the experiment

The experiment was carried out on the Charpy notched pendulum test machine of CAAC, based on the standard GB/T 2292007. The size of the sample is $10 \mathrm{~mm} \times 10 \mathrm{~mm} \times 55 \mathrm{~mm}$, the opening is $\mathrm{U}$-shaped, the groove depth is $2 \mathrm{~mm}$, and the radius of the groove bottom is $1 \mathrm{~mm}$. The experimental temperatures were $-60{ }^{\circ} \mathrm{C},-40{ }^{\circ} \mathrm{C},-20{ }^{\circ} \mathrm{C}, 23{ }^{\circ} \mathrm{C}, 100{ }^{\circ} \mathrm{C}, 200{ }^{\circ} \mathrm{C}$ and $300{ }^{\circ} \mathrm{C}$, respectively. The microstructure of the materials was observed by metallographic microscope and JSM-6460 tungsten lamp scanning electron microscope after holding $30 \mathrm{~min}$ at a fixed temperature.

\section{$\underline{3 \text { Results and discussions }}$}

Figure 2 shows the transition curve of impact properties of Ti6211 titanium alloy at different temperatures by fitting the data of seven points at different temperatures. It can be seen from the diagram that the impact energy of the alloy increases gradually with the increase of temperature, and is obviously divided into three stages. The impact work increases slowly below room temperature, increases sharply from room temperature to $200{ }^{\circ} \mathrm{C}$, and slows down when the temperature is above $200{ }^{\circ} \mathrm{C}$, which is consistent with the theoretical change.

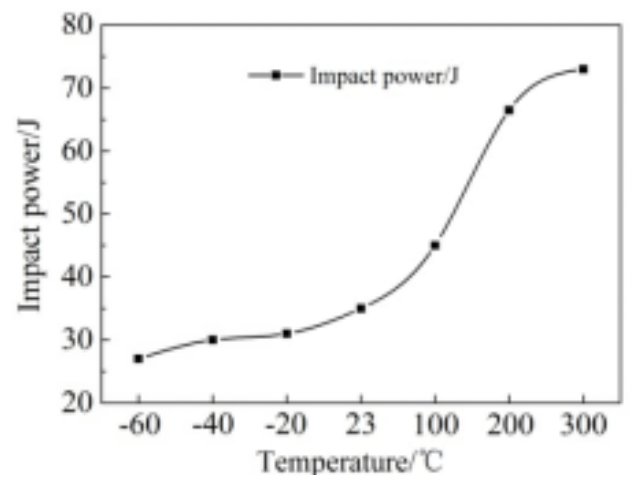

Fig 2 The change curve of impact properties of the alloy at different temperatures

Figure 3 shows the impact fracture morphology of seven alloy samples at different temperatures. The fracture morphology of $\mathrm{A} \sim \mathrm{G}$ is $-60{ }^{\circ} \mathrm{C},-40{ }^{\circ} \mathrm{C},-20{ }^{\circ} \mathrm{C}, 23{ }^{\circ} \mathrm{C}, 100{ }^{\circ} \mathrm{C}, 200{ }^{\circ} \mathrm{C}$ and $300{ }^{\circ} \mathrm{C}$, respectively. From the macroscopic appearance of the image, the impact fracture at seven different temperatures is still composed of three parts ${ }^{[1]}$, the fiber region (marked a), the radiation region (marked c) and the shearing lip region (marked b). The crack forming zone, crack propagation zone and shear fracture zone are represented respectively. The fiber region and the shear lip area are ductile fracture, and the fracture surface may be perpendicular or tilt to the tensile stress, respectively known as positive fracture and oblique fracture, from the macro point of view, the fracture has a fine concave and convex, fibrous; The radiation region is brittle fracture, and the fracture surface is usually perpendicular to the tensile stress, and the macroscopic fracture is composed of shiny crystalline bright surface. When the radiation area reaches half of the fracture area, the corresponding fracture temperature is the ductile-brittle transition temperature of the alloy ${ }^{[1]}$. With the increase of temperature, the area of fiber area and shear lip area increases obviously, and the area of radiation area decreases. When the temperature is $200^{\circ} \mathrm{C}$ and $300^{\circ} \mathrm{C}$, the fracture surface can also see the ductile ridge produced by tear obviously, which indicates that before the fracture, produced greater plasticity deformation ${ }^{[2-3]}$. It is shown that the impact fracture of the alloy changes from brittleness to toughness with the increase of temperature. 

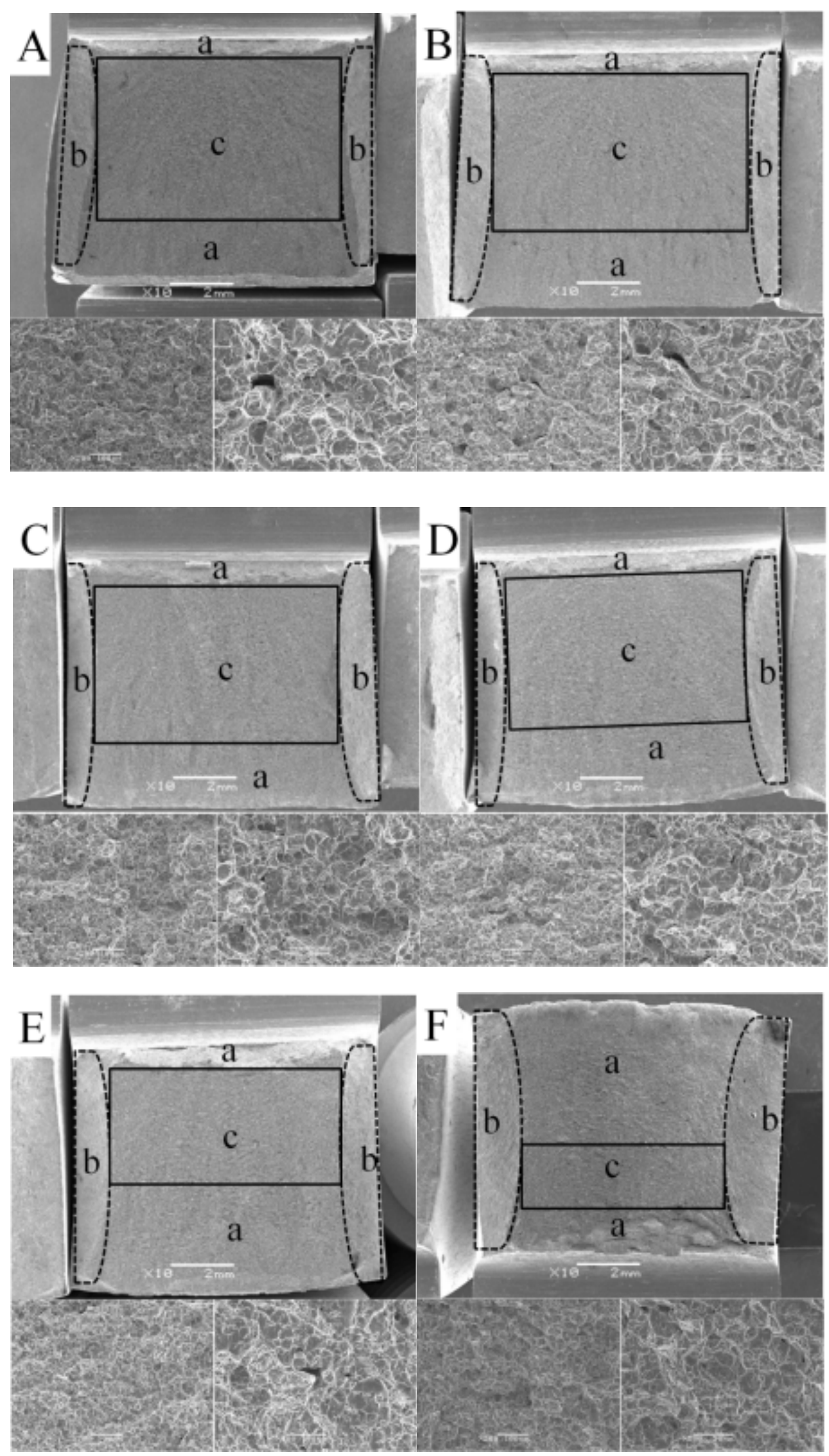


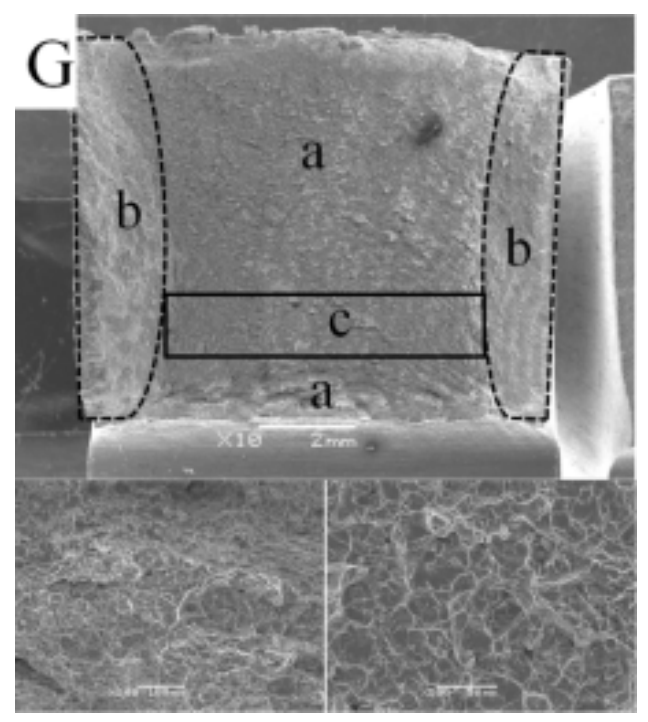

Fig $3 \mathrm{~A} \sim \mathrm{G}$ are the morphology of impact fracture at $-60^{\circ} \mathrm{C} 、-40^{\circ} \mathrm{C} 、-20^{\circ} \mathrm{C} 、 23^{\circ} \mathrm{C} 、 100^{\circ} \mathrm{C} 、 200^{\circ} \mathrm{C}$ and 300 , respectively

It can be seen from the microscopic morphology of the diagram that there are dimples and the secondary crack and the cleavage surface in the impact section at different temperatures, its quasi-cleavage fracture with ductile-brittle bonding. When the temperature is below room temperature, there are many secondary cracks and cleavage surfaces, the fracture surface of the alloy is mainly brittle fracture, and the fracture surface at four different temperatures has little difference. When the temperature reaches $100{ }^{\circ} \mathrm{C}$ or above, the number of dimples on the fracture surface increases obviously, the secondary crack and the cleavage surface decreases. The fracture are ductile fracture, and the fracture surface is different at the three temperatures. Fig. 4 shows the area ratio of impact fracture area at different temperatures. It can be seen from the graph, With the increase of temperature, the area ratio of fracture radiation area decreases gradually, and the decrease is slower below room temperature, and decreases sharply between room temperature and $200{ }^{\circ} \mathrm{C}$. It can be inferred from the diagram that the ductile-brittle transition temperature of the alloy is about $50{ }^{\circ} \mathrm{C}$.

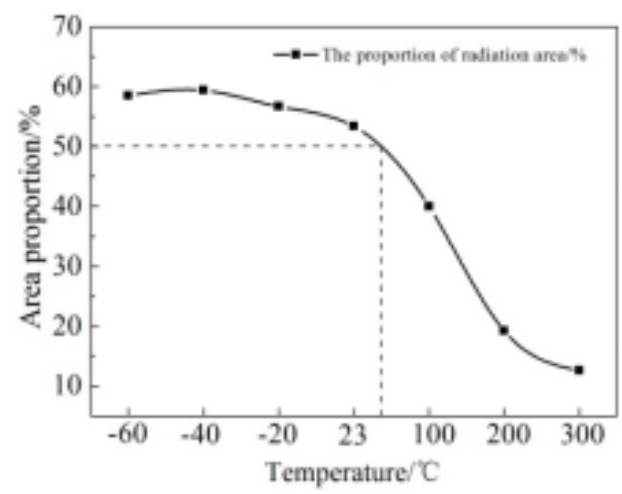

Fig 4 The proportion of the radiation area of the material impact fracture at dirrefent temperature

The impact test is carried out at a set temperature for a short time, and the experimental process is short, so the microstructure of the sample will not be affected obviously ${ }^{[4]}$. Therefore, the main factor causing the difference of impact properties at different temperatures is dislocation movement ability. When the temperature is low, the impact force on the notch of the impact specimen is not enough to break through the F-R source near the stress concentration, and the dislocation is not easy to produce and start, resulting in less plastic deformation area, more radiation zone and more microcracks ${ }^{[5]}$. When the temperature increases, the impact deformation can make the pinned dislocation slip, resulting in a certain plastic deformation, fracture tear, create more dimples.

\section{Conclusion}

The main results are as follows: 
(1) With the increase of temperature, the impact energy of the material increases continuously, and when the temperature is above $0{ }^{\circ} \mathrm{C}$, the increase of impact energy is obvious, and when the temperature exceeds $200{ }^{\circ} \mathrm{C}$, the increase of impact energy becomes slower.

(2) With the increase of temperature, the radiation area of the impact fracture surface gradually decreases. It can be inferred that the ductile-brittle transition temperature of the alloy is about $50^{\circ} \mathrm{C}$.

\section{Acknowledgments}

The author thanks to Dr. Fang Hao, Master Xu Enen and Master Du Junqi for their help in writing the thesis. All the work has been done in Western Superconducting Materials Technology Co., Ltd.

\section{$\underline{6 \text { References }}$}

[1] Li Weijun, Li Qing, Wei Lei.Study on the application of Charpy impact test for metallic materials[J]. Value Engineering. 2018, 04: $121 \sim 124$

[2] Liu Chaoping. Effect of Hot-working Technology on Microstructure and Properties of TC4-DT Titanium Alloy(D).2011.6

[3] Liu Yingying, Zhang Junyan, Wang Mengting et al. Impact Properties and fracture Analysis of TC18 Titanium Alloy bars and forgings[J]. Rare Metals.2018.9

[4] Hou Yanrong, Lai Yunjin, Du Yuxuan et al. Effect of Heat treatment on impact Properties of TA15 Titanium Alloy Bar[J]. Hot Working Technology, 2011, 40(2): 182 183

[5] Zhang Zhixin. Li Ruifeng, Wang Jian. Effect of test temperature on impact toughness of marine Ti70 titanium alloy sheet[J]. Metallurgical smelting and chemical industry. 2017, 08: 1 3 